\title{
The Pattern of Bilirubin Response to Phototherapy for Neonatal Hyperbilirubinaemia
}

\author{
K. L. TAN ${ }^{(14)}$ \\ Department of Paediatrics, National University of Singapore, Singapore
}

\begin{abstract}
Summary
The pattern of bilirubin response to phototherapy was studied using lamps with an emission spectrum closely similar to the bilirubin absorption spectrum. A dose-response relationship was demonstrated, with increased intensity of phototherapy resulting in greater response; however, the rate of bilirubin decline progressively decreased with increasing radiance till a 'saturation' point was reached, beyond which no further response occurred with further increase in radiance, suggesting a curvilinear relationship of the nature of an asymptotic regression. At the 'saturation' point, a 24-h decline of about $50 \%$ was achieved.

With extended periods of phototherapy, a gradually decreasing response to phototherapy with declining bilirubin levels was observed, both with maximal or moderate intensity phototherapy; an exponential regression was suggested. At about $5 \mathrm{mg} / \mathrm{dl}$ little further decline was observed with continued phototherapy. The rate of the 24-h decline evaluated at 6-h intervals was observed to be proportional to the bilirubin level at the start of the 24-h period.
\end{abstract}

The pattern of bilirubin response to phototherapy has not been clearly defined before. Although the nature of the dose-response relationship of phototherapy for neonatal hyperbilirubinaemia has been documented (9), the pattern of bilirubin decline in neonates in response to continuous phototherapy over extended periods has never been reported as far as can be ascertained. Furthermore, it has been suggested that the spectral emission curves of the lamps employed in the dose-response study were not altogether suitable for such an investigation (1).

With the availability of lamps with a spectral emission curve closely approximating to the bilirubin absorption curve, it was thought that an investigation into the pattern of the bilirubin decline in response to increasing light radiance, as well as extended periods of phototherapy would be worthwhile. The following paper is an attempt at such a study.

\section{MATERIALS AND METHODS}

Two studies were performed: the first investigated the doseresponse relationship, and the second the bilirubin decline over an extended period of phototherapy. Informed consent was obtained.

In the first study, fullterm 'healthy' infants with nonhaemolytic hyperbilirubinaemia as previously defined (10) were divided into nine matched groups based on the following parameters: birth weight, gestational and postnatal age and haemoglobin $(\mathrm{Hb})$ and bilirubin levels at onset of phototherapy. Phototherapy was provided by stationary frames to which were attached Philips TL20W/52 lamps with a spectral emission curve closely similar to the bilirubin absorption curve (Fig. 1). A system of switches was employed to provide different light intensities. Each group of infants was exposed to phototherapy of different radiance, the phototherapy commencing in the morning. The light measurements were made by the $11 \mathrm{~A}$ photometer/radiometer (United Detector Technology Inc., USA) as described previously (10).
Each infant was exposed unclothed (except for eye pads) to continuous phototherapy interrupted only for feeding, nursing and 6-h capillary blood sampling for bilirubin determination. Feeds were increased during phototherapy to offset the tendency to greater fluid loss (5). During blood sampling the lights were switched off, the blood collected in capillary tubes, placed in labeled red coloured straws, and kept in a light tight box until the moment of bilirubin determination. Phototherapy was only discontinued when the bilirubin level had declined below $11 \mathrm{mg} / \mathrm{dl}$, the minimum period of exposure being $48 \mathrm{~h}$. After cessation of phototherapy, daily bilirubin levels were monitored until a static or declining trend was observed, the minimal period being 2 days. Total bilirubin was determined under uniform conditions by an AO Bilirubinometer (American Optical Corp., USA), the results correlating well with those by the method of Malloy and Evelyn (3). Direct acting bilirubin was determined in random samples by the method of Malloy and Evelyn (3).

The second study was started only after the first study had been evaluated. Two intensities of light were selected for this study, one for moderate response, and the other for maximal response, hereafter referred to as moderate and maximal intensity phototherapy respectively; the light radiance corresponded to those of groups 5 and 7 respectively of the first study. The decision to select a radiance corresponding to group 5 for moderate intensity phototherapy was based on the desire for a light radiance that, though obviously less than that of maximal intensity phototherapy, was still able to elicit a pattern of bilirubin response (decline) within an acceptable period of exposure, a situation probably not possible with a lesser radiance.

Fullterm 'healthy' infants with nonhaemolytic hyperbilirubinaemia were divided into two groups, the first being exposed to moderate intensity phototherapy for 4 continuous days, and the second to maximal intensity phototherapy for 3 continuous days. The infants were nursed in the same manner as in the first study, with capillary blood sampling at 6-h intervals. To offset the effect of diurnal variation of bilirubin levels on the 6-h evaluation of mean bilirubin values, each infant within each group was started on phototherapy at a different time during daylight hours.

The results were subjected to statistical evaluation.

\section{RESULTS}

All the infants in both studies were well before, during and after phototherapy. Increased ventilation from an overhead ceiling fan was required to maintain normothermia in those exposed to high intensity phototherapy from multiple lamps. As previously observed $(9,10)$, bilirubin levels varied with the time of the day. On no occasion did the direct acting bilirubin exceed $1 \mathrm{mg} / \mathrm{dl}$ in the random samples determined.

In the first study (Table 1), the only reliable criterion for assessing the efficacy of phototherapy was the 24-h decline in bilirubin values during phototherapy; the 24-h decline was expressed as a proportion of the initial bilirubin value. A doseresponse relationship was observed (Table 2) with the rate of decline becoming progressively less with increased radiance until 
a 'saturation' point was reached, beyond which no further decline occurred with further increase in radiance (Fig. 2), suggesting an asymptotic regression; at 'saturation' point a decline of about $50 \%$ was observed. A semi-logarithmic presentation of the results demonstrated a linear relationship (Fig. 3); by extrapolation the dosage of light for minimal effectiveness was $31.85 \mu \mathrm{Watts} / \mathrm{cm}^{2}\left(\mu \mathrm{W} / \mathrm{cm}^{2}\right)$

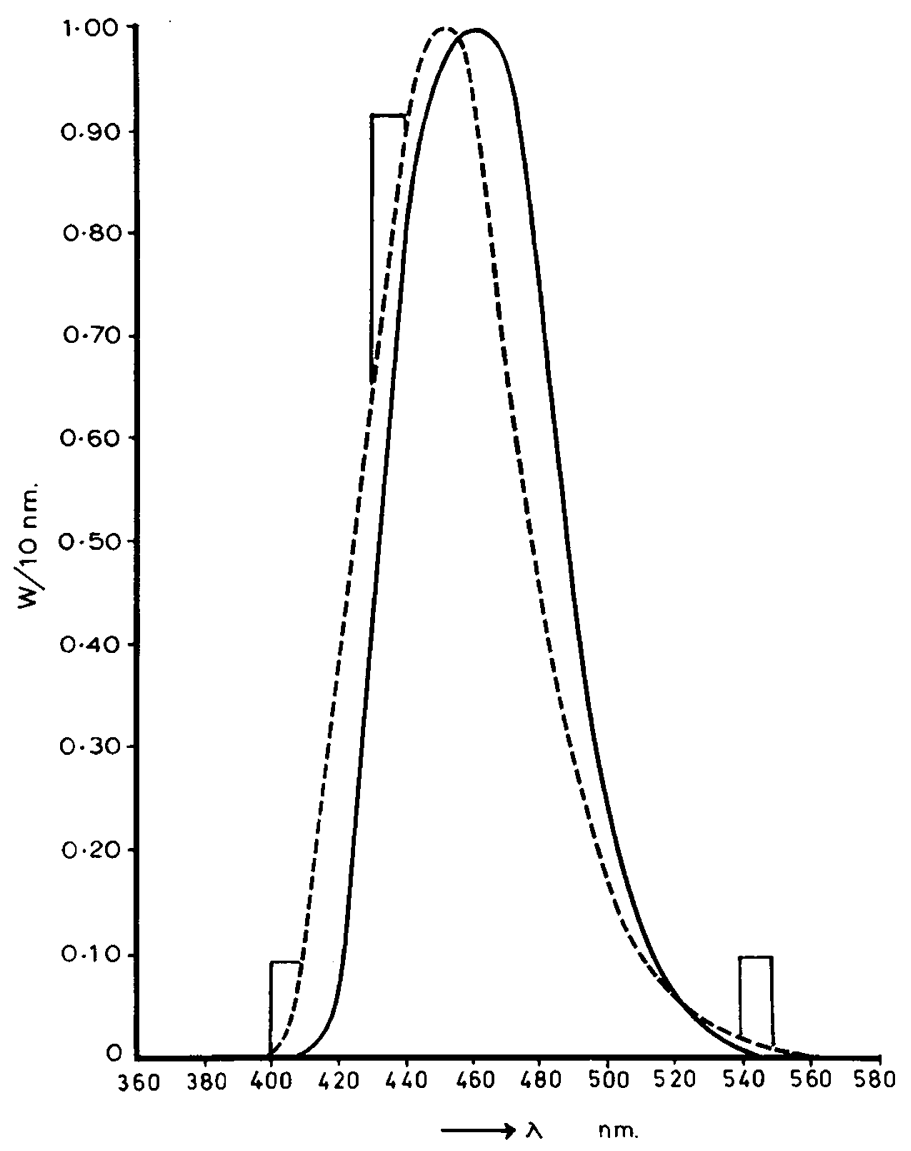

Fig. 1. The spectral emission curve of the Philips TL20W/52 lamp (broken line) compared with the bilirubin absorption curve (solid line); the vertical bars are the mercury spectral bands. for the 440-480 nanometer (nm) range, $50.26 \mu \mathrm{W} / \mathrm{cm}^{2}$ for the $425-475 \mathrm{~nm}$ range, and $54.71 \mu \mathrm{W} / \mathrm{cm}^{2}$ for the $400-480 \mathrm{~nm}$ range. Two infants in Group 1 experienced a rise in $24-\mathrm{h}$ bilirubin levels and had to be removed from the study for more effective treatment. The number of infants with $24-\mathrm{h}$ bilirubin values below 11 $\mathrm{mg} / \mathrm{dl}$ were greater in the groups exposed to more intense phototherapy. The second $24-\mathrm{h}$ decline was less marked than the first 24-h decline; however, no valid comparisons could be made among the groups as the mean bilirubin values of the groups at the start of this second period were no longer comparable. Postphototherapy rebound in bilirubin levels was generally mild in all nine groups.

In the second study (Table 3 ), the infants commenced phototherapy at different times within each study group; thus, virtually eliminating the effect of diurnal variation of bilirubin levels on the overall mean values. The bilirubin levels declined with continued phototherapy (Table 4), with the rate of decline decreasing with declining values; at about $5 \mathrm{mg} / \mathrm{dl}$ very little further decline with continued phototherapy was observed in both groups of infants (Fig. 4). An exponential regression was suggested. Semilogarithmic presentation of the results demonstrated a linear relationship (Fig. 5). The $24-\mathrm{h}$ bilirubin declines were evaluated at 6-h intervals, each decline being expressed as a proportion of the bilirubin value at the commencement of the 24-h period. A linear relationship was observed between the 24-h declines and the bilirubin values at the start of the 24-h periods (Fig. 6) especially in the group subjected to high intensity phototherapy, demonstrating that the rate of decline was directly proportional to the bilirubin value at the start of the $24-h$ period. Only a mild postphototherapy rebound was observed. The end of phototherapy, $\mathrm{Hb}$ and PCV values were not significantly different between the two groups (Fig. 3).

\section{DISCUSSION}

Previous studies $(4,8)$ have demonstrated the dose-response relationship of phototherapy for neonatal hyperbilirubinaemia. That the response was related to the logarithm of the radiance was later reported both in the neonate (9) and the Gunn rat (2). The present study confirms the asymptotic nature of the doseresponse relationship of a previous study (9) by the same author. At the 'saturation' point, however, a much greater reduction in bilirubin levels was observed i.e., about $50 \%$ compared with about $37 \%$ in the earlier study (9). This increased efficacy was obviously

Table 1. Data of the nine groups of infants

\begin{tabular}{|c|c|c|c|c|c|c|c|c|c|c|}
\hline & & & & & & Groups & & & & \\
\hline . & & 1 & 2 & 3 & 4 & 5 & 6 & 7 & 8 & 9 \\
\hline No. (M:F) & & $12(8: 4)$ & $12(7: 5)$ & $12(9: 3)$ & $12(8: 4)$ & $12(6: 6)$ & $12(7: 5)$ & $12(7: 5)$ & $12(8: 4)$ & $12(8: 4)$ \\
\hline Age (days) & & & & & & & & & & \\
\hline No. at 3 days & & 6 & 6 & 6 & 6 & 6 & 6 & 6 & 6 & 6 \\
\hline No. at 4 days & & 4 & 4 & 4 & 4 & 4 & 4 & 4 & 4 & 4 \\
\hline No. at 5 days & & 2 & 2 & 2 & 2 & 2 & 2 & 2 & 2 & 2 \\
\hline Gest $^{n}(w k)$ & Mean & 39.2 & 38.8 & 39.0 & 39.3 & 39.0 & 39.7 & 39.1 & 39.1 & 38.8 \\
\hline & S.E. & 0.3 & 0.4 & 0.3 & 0.3 & 0.4 & 0.4 & 0.3 & 0.4 & 0.3 \\
\hline Birth wt (g) & Mean & 2783 & 2988 & 3074 & 2920 & 2940 & 3279 & 3045 & 3213 & 3034 \\
\hline & S.E. & 133 & 106 & 113 & 98 & 106 & 154 & 113 & 150 & 90 \\
\hline $\mathrm{Hb}(\mathrm{gm} / \mathrm{dl})$ & Mean & 18.3 & 17.9 & 17.9 & 16.4 & 17.5 & 17.0 & 16.5 & 17.2 & 17.8 \\
\hline & S.E. & 0.7 & 0.6 & 0.7 & 0.6 & 0.4 & 0.6 & 0.6 & 0.6 & 0.6 \\
\hline Bilirubin (mg/dl) & Mean & 15.7 & 16.0 & 16.3 & 16.9 & 17.7 & 17.5 & 17.8 & 17.5 & 17.3 \\
\hline & S.E. & 0.1 & 0.3 & 0.4 & 0.5 & 0.7 & 0.5 & 0.5 & 0.5 & 0.5 \\
\hline Phototherapy & & & & & & & & & & \\
\hline Foot-candles & & 14 & 44 & 52 & 70 & 110 & 160 & 175 & 207 & 243 \\
\hline Lux & & 150 & 473 & 559 & 753 & 1183 & 1721 & 1883 & 2227 & 2614 \\
\hline Radiance $(\mu \mathrm{W} / \mathrm{cm}$ & & & & & & & & & & \\
\hline $400-480 \mathrm{~nm}$ & & 146 & 489 & 573 & 678 & 1206 & 1766 & 1851 & 2203 & 2541 \\
\hline $425-475 \mathrm{~nm}$ & & 134 & 447 & 523 & 619 & 1101 & 1612 & 1690 & 2011 & 2319 \\
\hline $440-480 \mathrm{~nm}$ & & 85 & 284 & 333 & 394 & 701 & 1027 & 1076 & 1281 & 1477 \\
\hline
\end{tabular}


Table 2. Bilirubin decline

\begin{tabular}{|c|c|c|c|c|c|c|c|c|c|c|}
\hline & & \multicolumn{9}{|c|}{ Groups } \\
\hline & & 1 & 2 & 3 & 4 & 5 & 6 & 7 & 8 & 9 \\
\hline \multirow[t]{2}{*}{ Bilirubin level (mg/dl) } & Mean & 15.7 & 16.0 & 16.3 & 16.9 & 17.7 & 17.5 & 17.8 & 17.5 & 17.3 \\
\hline & S.E. & 0.1 & 0.3 & 0.4 & 0.5 & 0.7 & 0.5 & 0.5 & 0.5 & 0.5 \\
\hline \multirow{2}{*}{$\begin{array}{l}\text { 24- } \mathrm{h} \text { bilirubin level } \\
\qquad(\mathrm{mg} / \mathrm{dl})\end{array}$} & Mean & 13.0 & 12.1 & 11.6 & 11.6 & 10.9 & 10.4 & 8.9 & 8.9 & 8.7 \\
\hline & S.E. & 0.7 & 0.4 & 0.4 & 0.5 & 0.7 & 0.5 & 0.6 & 0.4 & 0.3 \\
\hline \multirow{2}{*}{ 24-h bilirubin decline (\%) } & Mean & 17.0 & 23.8 & 28.2 & 31.2 & 38.3 & 45.5 & 51.1 & 49.2 & 49.6 \\
\hline & S.E. & 4.4 & 2.3 & 2.0 & 1.7 & 3.0 & 1.9 & 3.0 & 2.0 & 2.2 \\
\hline $\begin{array}{l}\text { No. of babies with } 24-\mathrm{h} \\
\text { bilirubin }<11 \mathrm{mg} / \mathrm{dl}\end{array}$ & & 2 & 2 & 4 & 5 & 8 & 11 & 11 & 10 & 12 \\
\hline \multirow{2}{*}{$\begin{array}{l}\text { 48- } \mathrm{h} \text { bilirubin level } \\
(\mathrm{mg} / \mathrm{dl})\end{array}$} & Mean & $10.5^{1}$ & 10.1 & 9.3 & 8.5 & 8.2 & 6.4 & 6.3 & 6.5 & 5.7 \\
\hline & S.E. & 0.7 & 0.5 & 0.6 & 0.6 & 0.4 & 0.5 & 0.6 & 0.3 & 0.4 \\
\hline \multirow{2}{*}{$\begin{array}{l}\text { 2nd 24-h bilirubin } \\
\text { decline }(\%)\end{array}$} & Mean & $14.8^{1}$ & 17.1 & 18.9 & 27.3 & 22.0 & 35.9 & 32.7 & 30.4 & 33.9 \\
\hline & S.E. & 3.7 & 3.0 & 6.1 & 4.4 & 3.7 & 5.0 & 5.4 & 2.5 & 3.9 \\
\hline \multicolumn{2}{|l|}{$\begin{array}{l}\text { No. of babies with } 48-\mathrm{h} \\
\text { bilirubin }<11 \mathrm{mg} / \mathrm{dl}\end{array}$} & 6 & 7 & 9 & 9 & 12 & 12 & 12 & 12 & 12 \\
\hline \multicolumn{11}{|l|}{$\begin{array}{l}\text { Postphototherapy biliru- } \\
\text { bin level }(\mathrm{mg} / \mathrm{dl})\end{array}$} \\
\hline \multirow[t]{2}{*}{ 1st day } & Mean & 9.8 & 10.8 & 9.5 & 8.8 & 9.1 & 8.3 & 8.0 & 7.9 & 7.5 \\
\hline & S.E. & 0.4 & 0.5 & 0.6 & 0.6 & 0.5 & 0.4 & 0.7 & 0.5 & 0.5 \\
\hline \multirow[t]{2}{*}{ 2nd day } & Mean & 10.1 & 11.0 & 10.4 & 9.7 & 10.5 & 9.2 & 9.5 & 8.6 & 8.4 \\
\hline & S.E. & 0.6 & 0.6 & 0.7 & 0.7 & 0.6 & 0.6 & 0.5 & 0.5 & 0.7 \\
\hline
\end{tabular}

${ }^{1}$ Two infants removed from the study group after 24 -h phototherapy because of rising bilirubin levels.

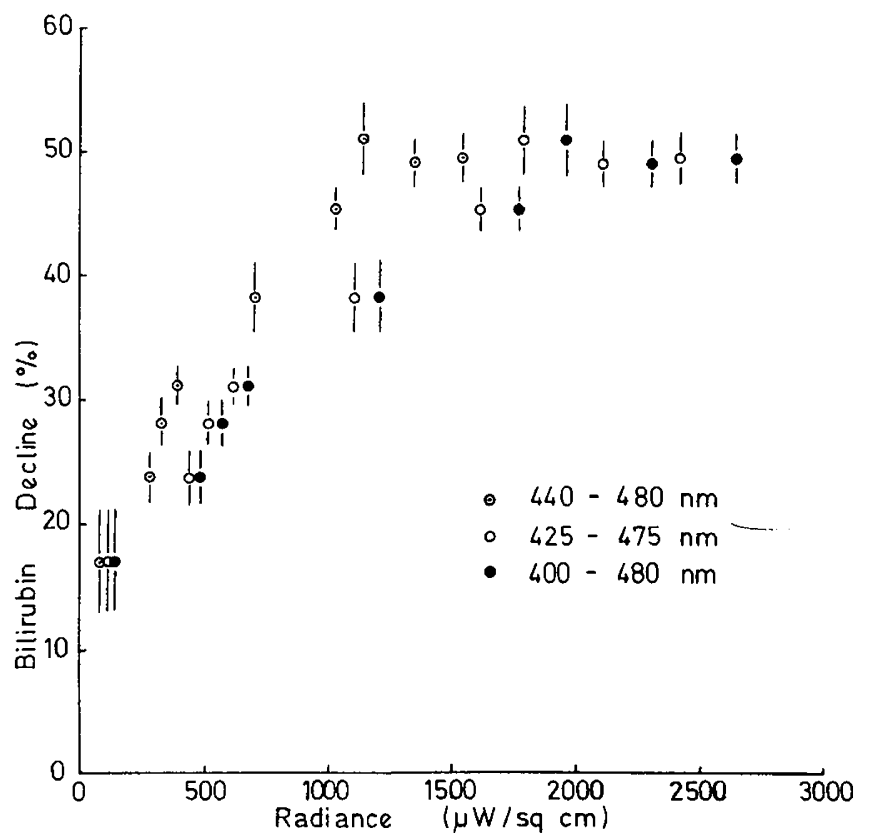

Fig. 2. The 24-h decline in bilirubin values (mean \pm S.E.) expressed as a proportion of the initial bilirubin levels, in response to increasing radiance.

the result of the lamps used in the present study having a more effective spectral emission curve.

In contrast to the failure to find a limitation effect of phototherapy at even very high radiances by Wiese and Ballowitz (13), the present study demonstrated a 'saturation' point, the radiance of which in the relevant waveband was about the same as that of a previous report (7). This 'saturation' point radiance and also the radiance for minimal effectiveness were much higher than those (Fig. 7) reported by the author earlier (9), a surprising observation. These differences were too great to be attributed to measurement errors. The measurements made, however, involved narrow wavebands, which though of major importance with regard to phototherapeutic effect, did not include other wavelengths which may be of some effect in phototherapy though less so (6). This is

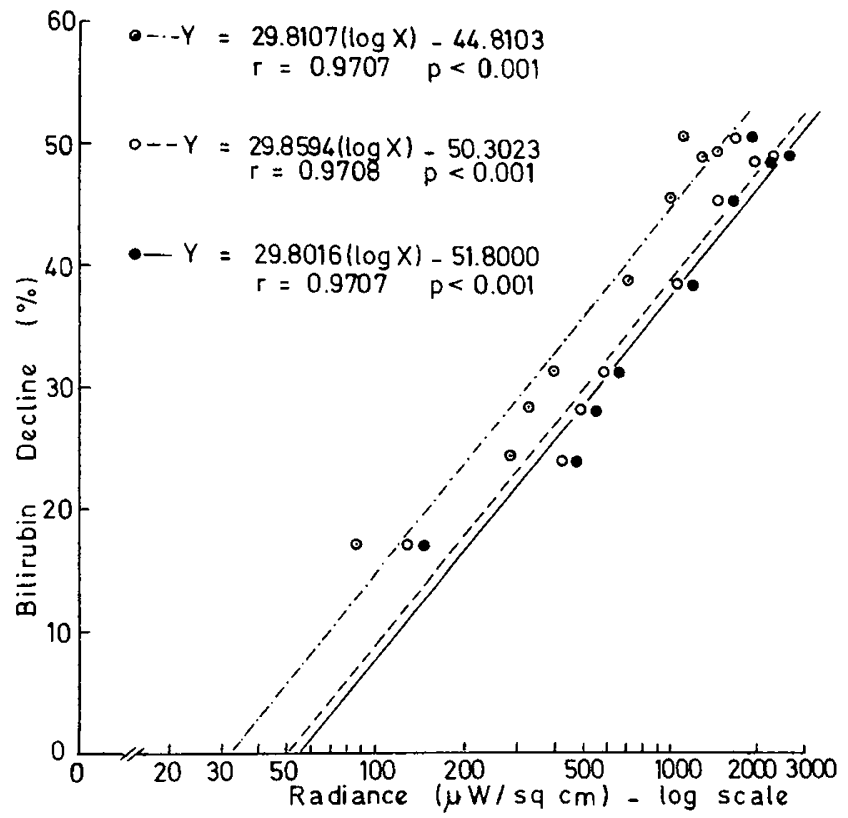

Fig. 3. Semi-logarithmic presentation of the 24-h decline; a linear relationship was observed.

especially relevant in the extrapolated minimal effective dose. In the previous study, broad spectrum daylight lamps were used for the lower radiance levels and narrow spectrum blue/violet lamps for the higher radiance levels. This would also explain the convergence of the regression curves on semi-logarithmic presentation. The almost parallel regression curves in the present report was the result of the use of the same type of lamp throughout the whole study.

In the second study, the effect of diurnal variation on bilirubin values was virtually eliminated by commencing phototherapy at different times for each infant within each study group. An exponential regression was suggested. Such an observation had previously been made in Gunn rats $(11,12)$. In these studies, a lesser maximal response for lesser radiance (as calculated from the cumulative dosage of continuous and intermittent phototherapy regimes) was observed even for prolonged periods of photother- 
apy. Such a response was not observed in the present study even though the dosage of moderate intensity phototherapy was only about two-thirds of that of maximal intensity phototherapy; an equally low bilirubin value was obtained but after a longer duration of phototherapy. With bilirubin levels of $5 \mathrm{mg} / \mathrm{dl}$, further phototherapy would only be of minimal efficacy. The 24-h bilirubin declines were also demonstrated to be proportional to the bilirubin values at the start of the 24-h period; hence with low bilirubin values, a proportionately smaller response can be expected for the same intensity of phototherapy, whereas a greater response can be expected at high levels under comparable conditions.

Table 3. Date of the two groups of infants and phototherapy setup

\begin{tabular}{|c|c|c|c|}
\hline & & $\begin{array}{c}\text { Moderate } \\
\text { intensity }\end{array}$ & $\begin{array}{l}\text { Maximal } \\
\text { intensity }\end{array}$ \\
\hline No. (M:F) & & $14(7: 7)$ & $14(8: 6)$ \\
\hline \multirow[t]{2}{*}{ Birth wt (g) } & Mean & 2964 & 3060 \\
\hline & S.E. & 92 & 158 \\
\hline \multirow[t]{2}{*}{ Gest $^{n}(w k)$} & Mean & 38.4 & 38.8 \\
\hline & S.E. & 0.3 & 0.4 \\
\hline \multicolumn{4}{|l|}{ Age (days) } \\
\hline No. at 2 days & & 3 & 4 \\
\hline No. at 3 days & & 5 & 4 \\
\hline No. at 4 days & & 4 & 4 \\
\hline No. at 5 days & & 2 & 2 \\
\hline \multicolumn{4}{|l|}{$\mathrm{Hb}(\mathrm{g} / \mathrm{dl})$} \\
\hline \multirow[t]{2}{*}{ Start } & Mean & 17.8 & 17.9 \\
\hline & S.E. & 0.5 & 0.8 \\
\hline \multirow[t]{2}{*}{ End } & Mean & $17.5^{1}$ & $16.3^{1}$ \\
\hline & S.E. & 0.6 & 0.9 \\
\hline \multicolumn{4}{|l|}{ PCV $(\%)$} \\
\hline \multirow[t]{2}{*}{ Start } & Mean & 54.8 & 54.6 \\
\hline & S.E. & 1.9 & 2.7 \\
\hline \multirow[t]{2}{*}{ End } & Mean & $52.0^{1}$ & $48.1^{1}$ \\
\hline & S.E. & 1.5 & 2.3 \\
\hline Bilirubin & Mean & 17.1 & 18.4 \\
\hline$(\mathrm{mg} / \mathrm{dl})$ & S.E. & 0.4 & 0.4 \\
\hline \multicolumn{4}{|l|}{ Phototherapy } \\
\hline Foot-candles & & 110 & 175 \\
\hline Lux & & 1183 & 1883 \\
\hline \multicolumn{4}{|c|}{ Radiance $\left(\mu \mathrm{W} / \mathrm{cm}^{2}\right)$} \\
\hline $400-480 \mathrm{~nm}$ & & 1206 & 1851 \\
\hline $425-475 \mathrm{~nm}$ & & 1101 & 1690 \\
\hline $440-480 \mathrm{~nm}$ & & 701 & 1076 \\
\hline
\end{tabular}

\footnotetext{
${ }^{1} 0.3>p>0.2$
}

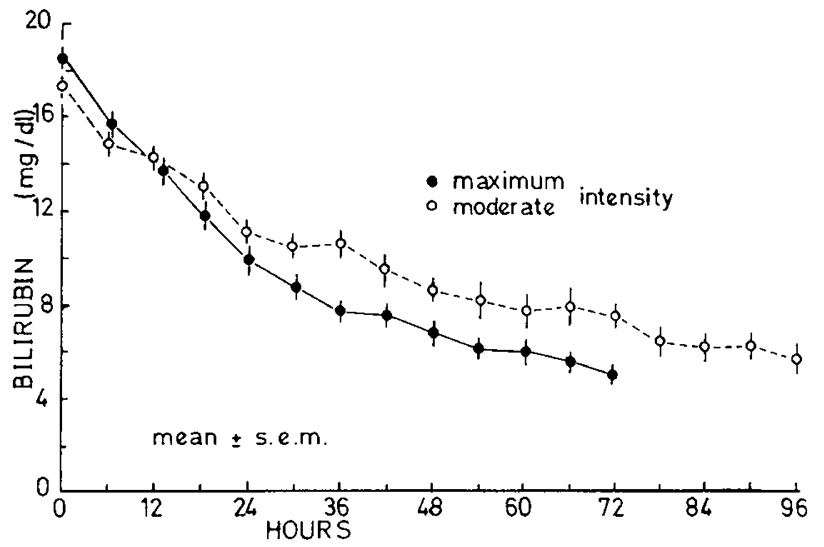

Fig. 4. Decline in bilirubin levels at 6-h intervals in response to extended periods of phototherapy, with maximal and moderate intensity phototherapy.

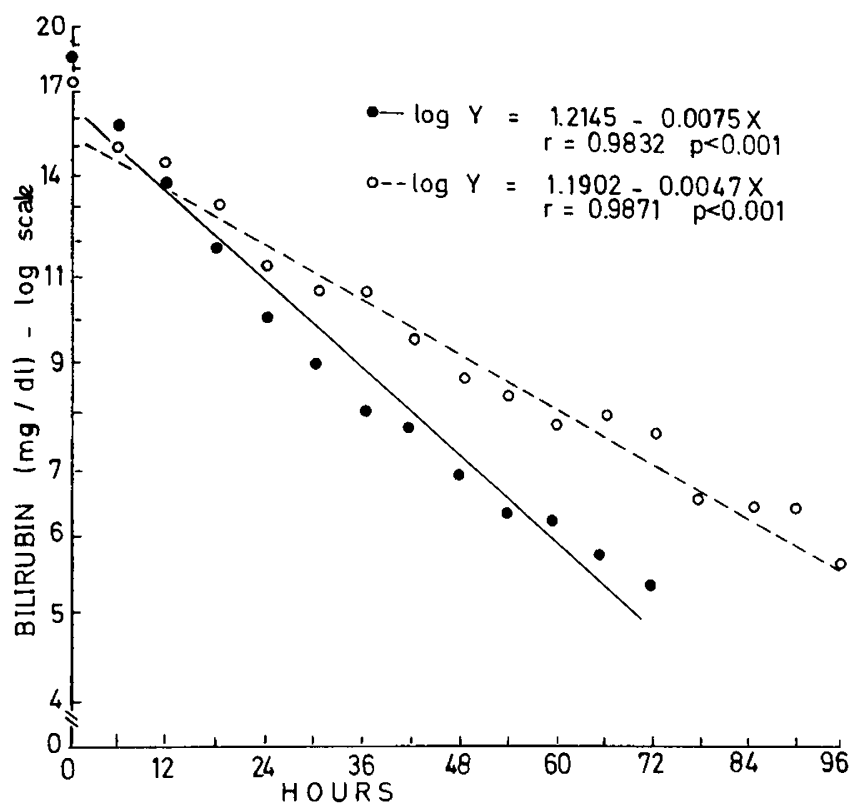

Fig. 5. Semi-logarithmic presentation of the 6-h decline; a linear relationship was demonstrated.

Table 4. Bilirubin values with phototherapy

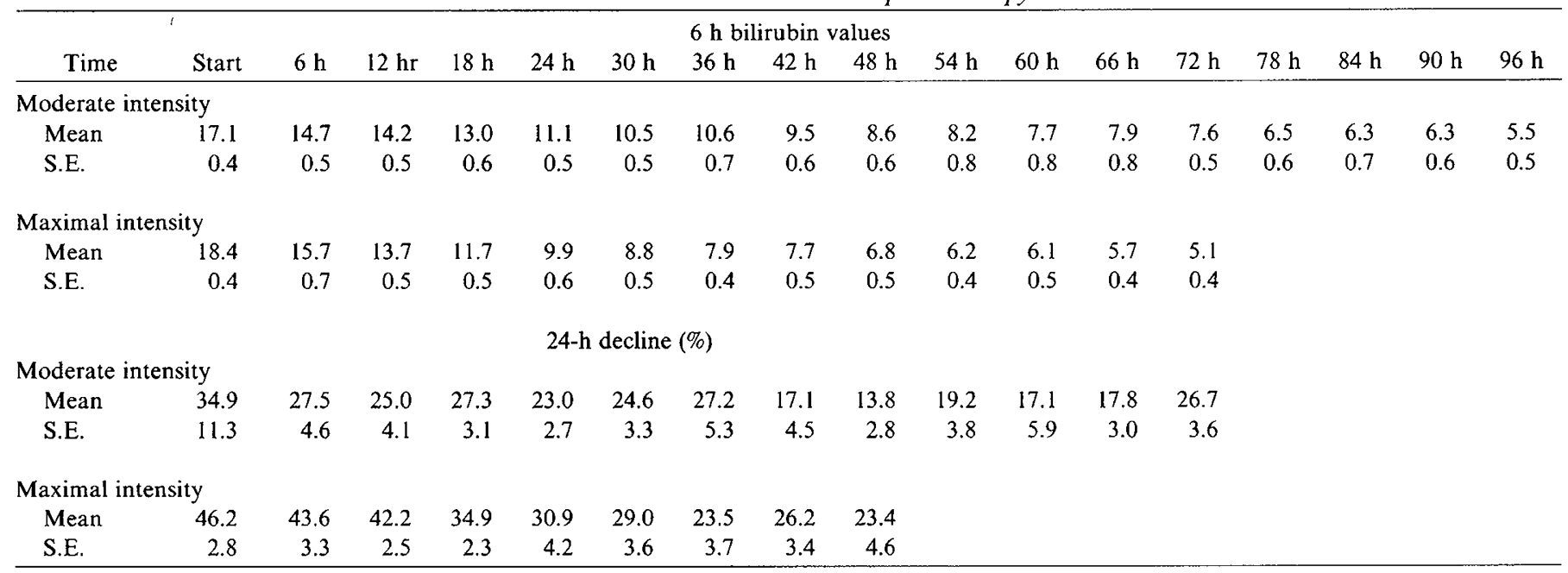




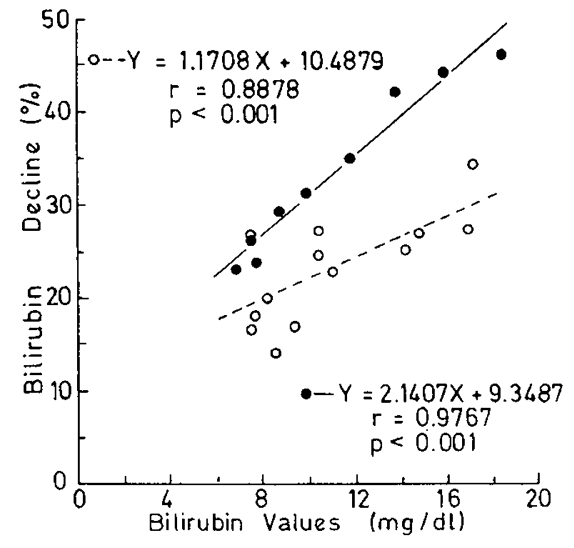

Fig. 6. The 24-h decline in bilirubin values expressed as a proportion of the bilirubin level at the start of the 24-h period. A linear relationship was observed.

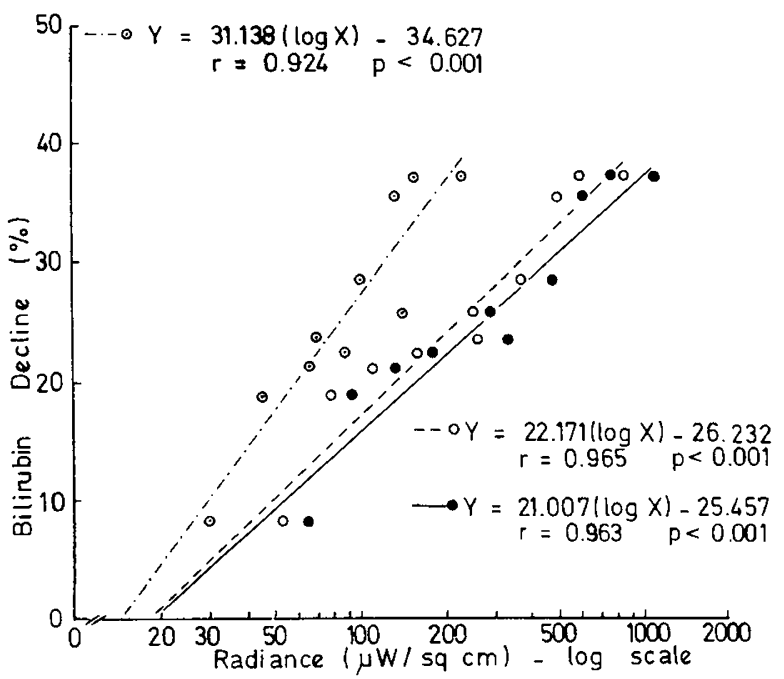

Fig. 7. A semi-logarithmic presentation of the dose-response relationship of a previous study (5) redrawn with the radiance values in the 440 $480 \mathrm{~nm}$ waveband added.
The ideal light intensity for phototherapy has yet to be defined. As demonstrated in this paper, differences in light intensity could result in different responses in bilirubin decline. Certainly in cases of severe hyperbilirubinaemia or rapidly progressive jaundice, where need for rapid control of the condition is obvious, it would be advisable to use high intensity phototherapy. The duration of phototherapy and the bilirubin levels at which cessation of treatment is indicated have also as yet not been clearly defined. The present study demonstrates that further phototherapy would be of minimal efficacy where bilirubin levels have declined to about 5 $\mathrm{mg} / \mathrm{dl}$. Postphototherapy rebound was also mild in jaundice due to nonhaemolytic causes.

\section{REFERENCES AND NOTES}

1. Ballowitz, L., Geutler, G., and Krachmann, J.: Dose-response relationship of phototherapy (letter). J. Pediatr., 92: 683 (1978).

2. Ballowitz, L., Geutler, G., Krochmann, J., Pannitschka, R., Roemer, G., and Roemer, I.: Phototherapy in Gunn rats. Biol. Neonate, 31: 229 (1977).

3. Malloy, H. and Evelyn, K. A.: The determination of bilirubin with the photoelectric colorimeter. J. Biol. Chem., 119: 481 (1937).

4. Mims, L. C., Estrada, M., Gooden, D. S., Caldwell, R. R., and Kotas, R. V.: Phototherapy for neonatal hyperbilirubinemia. A dose-response relationship. J. Pediatr., 83: 658 (1973).

5. Oh, W. and Karechi, H.: Phototherapy and insensible water loss in the newborn infant. Am. J. Dis. Child., 124: 230 (1972).

6. Raethel, H. A.: Wavelengths of light producing photodecomposition of bilirubin in serum from a neonate with hyperbilirubinemia. J. Pediatr., 87: 110 (1975).

7. Rubaitelli, E. F. and Granati, B.: Phototherapy of neonatal hyperbilirubinemia. Med. Biol. Environ., 8: 185 (1980).

8. Sisson, T. C. R., Kendall, N., Shaw, A., and Kechavarz-Oliai, L.: Phototherapy of neonatal jaundice in the newborn: II effect of various light intensities. J. Pediatr., 81: 35 (1972).

9. Tan, K. L.: The nature of the dose-response relationship of phototherapy for neonatal hyperbilirubinemia. J. Pediatr., 90: 448 (1977).

10. Tan, K. L.: Comparison of the effectiveness of single-direction and doubledirection phototherapy for neonatal jaundice. Pediatrics, 56: 550 (1975).

11. Vogl, T. P., Cheskin, H., Blumenfeld, T. A., Speck, W. T., and Koenigsberger, M. R.: Effect of intermittent phototherapy on bilirubin dynamics in Gunn rats. Pediatr. Res., 11: 1021 (1977).

12. Vogl, T. P., Cheskin, H. S., Blumenfeld, T. A., Sugai, G. K.: Bilirubin dynamics in the Gunn rat. Biol. Neonate, 38 : 106 (1980).

13. Wiese, G. and Ballowitz, L.: Mathematical derivation of dose-response relationship calculations in phototherapy. Pediatr. Res., 14: 1425 (1980).

14. Requests for reprints should be addressed to: Dr. K. L. Tan, Department of Paediatrics, Neonatal Unit, Kandang Kerbau Hospital, Singapore 0821, Republic of Singapore.

15. Received for publication September $9,1981$.

16. Accepted for publication February 1, 1981. 